Check for updates

Cite this: RSC Adv., 2017, 7, 31272

Received 18th April 2017

Accepted 4th June 2017

DOI: 10.1039/c7ra04361a

rsc.li/rsc-advances

\section{Facile synthesis of uniformly dispersed ZnO nanoparticles on a polystyrene/rGO matrix and its superior electrical conductivity and photocurrent generation}

\author{
M. Jeyavelan, ${ }^{a}$ A. Ramesh, ${ }^{a}$ R. Rathes Kannan, ${ }^{b}$ T. Sonia, ${ }^{a}$ K. Rugunandhiri ${ }^{a}$ \\ and M. Sterlin Leo Hudson (D) *a
}

Herein, a $\mathrm{ZnO} / \mathrm{PS} / \mathrm{rGO}$ composite was prepared via a simple reflex method and its microstructural and physical properties were characterized using XRD, SEM, HRTEM, TGA and FTIR, UV-visible, and PL spectroscopies. DC and AC electrical conductivities of the composite were measured using a four-point collinear probe method. The charge transfer resistance and photocurrent transient response were characterized via electrochemical impedance spectroscopy. It has been observed that in the ZnO/PS/ rGO composite, even a small amount of rGO (5 wt\%) effectively increases its electrical conductivity. PCTR and OCVD measurements revealed that the photocurrent response of ZnO was markedly improved when it was used in the composite $\mathrm{ZnO} / \mathrm{PS} / \mathrm{rGO}$ form; this suggested the viability of the $\mathrm{ZnO} /$ PS/rGO composite for practical applications.

\section{Introduction}

Semiconducting nanostructures have recently gained extensive interest owing to their potential applications in solar cells, nanoscale electronic devices, light-emitting diodes, laser technology, waveguide, chemical- and bio-sensors, photocatalysis, photoelectrodes etc $^{1-3}$ Among different semiconducting nanostructures, $\mathrm{ZnO}$ is a very promising candidate due to its wide direct band gap of $3.3 \mathrm{eV}$ at room temperature. Moreover, the absorption spectra of $\mathrm{ZnO}$ lies in the near-UV region, and it has a large room-temperature free-exciton binding energy of 60 meV. ${ }^{4}$ A recent study revealed that by altering the electronic configuration of $\mathrm{ZnO}$ nanoparticles through capping with organic molecules, it is possible to induce room-temperature ferromagnetic-like behavior without doping any magnetic impurities. ${ }^{5}$ Because of its unique properties, $\mathrm{ZnO}$ has attracted significant attention as an important semiconducting material for technological applications. ${ }^{4-6}$ Furthermore, the nano form of ZnO exhibits very high electron mobility of $\sim 1000 \mathrm{~cm}^{2} \mathrm{~V}^{-1}$ $\mathrm{s}^{-1}, 7,8$ which is more favorable for photoinduced electron collection in photovoltaic devices. ${ }^{\mathbf{9 1 0}}$ However, due to the intrinsic structural defects, $\mathrm{ZnO}$ has a low electrical conductivity of $7.261 \times 10^{-7} \mathrm{~S} \mathrm{~cm}^{-1}$ at room-temperature. ${ }^{11}$ Even in its nano form, $\mathrm{ZnO}$ exhibits electrical conductivity in the range from $10^{-6}$ to $10^{-4} \mathrm{~S} \mathrm{~cm}^{-1} .^{12}$ The low electrical conductivity of $\mathrm{ZnO}$

${ }^{a}$ Department of Physics, Central University of Tamil Nadu, Thiruvarur-610005, India. E-mail: msterlinleo@cutn.ac.in; Tel: +91-9486860214

${ }^{b}$ Department of Physics, Karunya University, Coimbatore-641114, India hinders its practical applications in photovoltaic devices, where improved electrical conductivity and low charge recombination loss are required for better photocurrent conversion efficiency. ${ }^{\mathbf{1 3}}$ More recently, graphene, a single, atomic thick 2D allotrope of carbon, has attracted significant attention due to its exceptional electrical, thermal, and mechanical properties associated with its unique structure consisting of $\mathrm{sp}^{2}$-hybridized carbon atoms packed in a two-dimensional honeycomb crystal lattice. ${ }^{\mathbf{1 4 - 1 8}}$ Graphene has an excellent electrical conductivity of $3.49 \times 10^{-2}$ $\mathrm{S} \mathrm{cm}^{-1} .^{19}$ Furthermore, graphene exhibits very high carrier mobility of $\sim 10000 \mathrm{~cm}^{2} \mathrm{~V}^{-1} \mathrm{~s}^{-1}$ at room temperature, ${ }^{20}$ high specific surface area of over $2000 \mathrm{~m}^{2} \mathrm{~g}^{-1},{ }^{21}$ good optical transparency of $\sim 97.7 \%,{ }^{22}$ high Young's modulus of nearly $1 \mathrm{TPa},{ }^{23}$ and high thermal conductivity in the range of $3000-5000 \mathrm{~W} \mathrm{~m}^{-1}$ $\mathrm{K}^{-1} \cdot{ }^{24}$ As a result of the abovementioned unique properties of graphene, graphene-based polymer composites have been reported to have superior electrical, mechanical, and thermal properties. $^{25-28}$ Polystyrene (PS) is one of the most widely used polymers for many commercial and industrial applications such as in home appliances, medical devices, automobiles etc. It has been reported that PS/reduced graphene oxide (rGO) composite shows superior electrical conductivity in the presence of a very small amount of rGO in the composite (for example: $0.2268 \mathrm{~S} \mathrm{~cm}^{-1}$ for $\mathrm{PS} / 4 \mathrm{wt} \% \mathrm{rGO}$ composite). ${ }^{23,30-32}$ Herein, we report the facile synthesis of a $\mathrm{ZnO} / \mathrm{PS} / \mathrm{rGO}$ composite, having $40 \mathrm{wt} \% \mathrm{ZnO}, 55 \mathrm{wt} \% \mathrm{PS}$, \& $5 \mathrm{wt} \% \mathrm{rGO}$, and its superior electrical conductivity (AC and DC) and high photocurrent response. The $\mathrm{ZnO} / \mathrm{PS} / \mathrm{rGO}$ composite may possess multiple applications in electronic devices such as highly 
efficient photoanodes in photovoltaic devices and flexible electronic applications.

\section{Experimental}

\subsection{Synthesis of graphite oxide (GO)}

Graphite oxide (GO) was prepared from graphite powder by a modified Hummers method. ${ }^{33}$ In each experiment, $2 \mathrm{~g}$ of graphite powder (Sigma Aldrich, 98\%) was mixed with $2 \mathrm{~g}$ of $\mathrm{NaNO}_{3}$ in $100 \mathrm{ml} \mathrm{H}_{2} \mathrm{SO}_{4}$ (98\%), followed by the slow addition of $12 \mathrm{~g} \mathrm{KMnO}_{4}$ under constant stirring in an ice-cooled bath. After about an hour of stirring at $0{ }^{\circ} \mathrm{C}$, the bath temperature was increased to $35{ }^{\circ} \mathrm{C}$ and stirring was continued for 2 hours. Afterwards, the bath temperature was further increased to $90{ }^{\circ} \mathrm{C}$, and $80 \mathrm{ml}$ of $\mathrm{H}_{2} \mathrm{O}$ was gradually added dropwise into the mixture. The mixture was then diluted with $200 \mathrm{ml}$ of $\mathrm{H}_{2} \mathrm{O}$, followed by the addition of $20 \mathrm{ml}$ of $30 \mathrm{wt} \% \mathrm{H}_{2} \mathrm{O}_{2}$ solution. The as-obtained brown dispersion was then subjected to centrifugation at $6500 \mathrm{rpm}$ for $20 \mathrm{~min}$. The mixture was rinsed and washed with $5 \% \mathrm{HCl}$ in deionized water. The resultant dark brown $\mathrm{GO}$ was dried at $80^{\circ} \mathrm{C}$ in a hot air oven.

\subsection{Preparation of the PS/rGO composite}

About $40 \mathrm{mg}$ of $\mathrm{GO}$ was dispersed in $20 \mathrm{ml}$ of $\mathrm{N}, \mathrm{N}$-dimethylformamide (DMF), and the solution $\left(2 \mathrm{mg} \mathrm{ml}^{-1}\right)$ was subjected to ultrasonic treatment for 2 hours at room temperature. Then, $800 \mathrm{mg}$ of polystyrene (PS), dissolved in $3 \mathrm{ml}$ of DMF, was added to the GO-dispersed DMF solution under constant stirring at $50{ }^{\circ} \mathrm{C}$. The temperature of the mixture was then increased to $80{ }^{\circ} \mathrm{C}$ and stirring was continued for 2 hours at $1000 \mathrm{rpm}$. Afterwards, $200 \mu \mathrm{l}$ of hydrazine hydrate was added dropwise to the mixture to reduce GO and stirring was continued at $90{ }^{\circ} \mathrm{C}$ for 14 hours until the mixture turned from brownish yellow to black. The hydrazine hydrate-treated GO has been denoted as reduced GO (rGO) throughout the manuscript. The mixture was then transferred to a large beaker and vigorously stirred with methanol to coagulate the composite, which was then filtered and dried overnight in a hot air oven at $80^{\circ} \mathrm{C}$. The resultant PS/rGO composite was obtained and subjected to further characterization.

\subsection{Synthesis of the $\mathrm{ZnO} / \mathrm{PS} / \mathrm{rGO}$ composite}

First, zinc precursor was prepared by dissolving $2 \mathrm{~g}$ of zinc acetate $\left(\mathrm{Zn}\left(\mathrm{CH}_{2} \mathrm{COO}\right)_{2} \cdot 2 \mathrm{H}_{2} \mathrm{O}\right)$ in $30 \mathrm{ml}$ DMF. The solution was stirred for $30 \mathrm{~min}$ at $40{ }^{\circ} \mathrm{C}$, followed by the addition of tetramethylammonium hydroxide ( $0.1 \mathrm{M}$ in $20 \mathrm{ml}$ of DMF). Then, the temperature of the mixture was increased to $120{ }^{\circ} \mathrm{C}$ and maintained for 3 hours until a milky white precipitate was formed. The as-prepared $\mathrm{PS} / \mathrm{rGO}$ solution was added to the abovementioned mixture under constant stirring and kept at $120^{\circ} \mathrm{C}$ for 6 hours. The composite was centrifuged (7000 rpm) for $15 \mathrm{~min}$ at $25^{\circ} \mathrm{C}$. The as-obtained composite was repeatedly washed with methanol and dried at $80^{\circ} \mathrm{C}$ in a hot air oven for 12 hours.

\subsection{Structural, microstructural, optical, and thermal analysis}

Structural analysis of the sample was carried out via X-ray diffraction (XRD) techniques using a Shimadzu X-ray diffractometer equipped with $\mathrm{Cu} \mathrm{K}$, radiation of wavelength $\lambda=$ $1.5401 \AA$. The microstructural morphologies of the samples were characterized using a JEOL scanning electron microscope (SEM) and a Tecnai $\mathrm{G}^{2} 20(200 \mathrm{kV})$ high resolution transmission electron microscope (HR-TEM). Fourier transform infrared (FTIR) spectra and Raman spectra were obtained using Perkin Elmer UATR Two and EZRaman-N-785 spectrometers, respectively. The optical absorption spectra were obtained between 200 and $800 \mathrm{~nm}$ using a Shimadzu UV-1800 spectrophotometer. Thermogravimetric analysis (TGA) of the samples was conducted between $35^{\circ} \mathrm{C}$ and $600{ }^{\circ} \mathrm{C}$ at the dynamical heating rate of $10^{\circ} \mathrm{C} \mathrm{min}^{-1}$ using a Perkin Elmer STA 8000 TGA analyser. The $\mathrm{PS}$ and $\mathrm{ZnO} / \mathrm{PS} / \mathrm{rGO}$ films, having the dimensions $80 \mathrm{~mm} \times$ $25 \mathrm{~mm} \times 0.8 \mathrm{~mm}$ and $80 \mathrm{~mm} \times 25 \mathrm{~mm} \times 1 \mathrm{~mm}$, respectively, were prepared via hot-press at $120^{\circ} \mathrm{C}$. The tensile properties of the as-prepared PS and $\mathrm{ZnO} / \mathrm{PS} / \mathrm{rGO}$ films were investigated using a universal testing machine (UTM) by employing ASTM D2256.

\subsection{Electrical and photoelectrochemical characterization}

DC electrical conductivity measurements were carried out using a Keithley 4200-SCS semiconductor characterization system along with an Everbeing INTL Corp four-point collinear probestation. The AC impedance spectra were obtained in the frequency range from $500 \mathrm{mHz}$ to $1 \mathrm{MHz}$ using a BioLogic VSP300 electrochemical workstation. The AC impedance, photocurrent transient response (PCTR), and open circuit voltage decay (OCVD) measurements were carried out using a BioLogic VSP-300 three-electrode cell electrochemical workstation, along with a standard three-compartment cell under UV light irradiation (300 W mercury lamp). Typically, for PCTR measurements, $2 \mathrm{~g}$ of $\mathrm{ZnO}$ or $\mathrm{ZnO} / \mathrm{PS} / \mathrm{rGO}$ composite was added to $2 \mathrm{ml}$ of ethanol to make a viscus paste, and it was coated on an ITO glass substrate, having sheet resistance of $8-12 \Omega \mathrm{sq}^{-1}$ (Sigma Aldrich), using a doctor-blading technique. The as-prepared $\mathrm{ZnO} / \mathrm{ITO}$ and $\mathrm{ZnO} / \mathrm{PS} / \mathrm{rGO} / \mathrm{ITO}$ films were dried at $200{ }^{\circ} \mathrm{C}$ on a hot plate for $30 \mathrm{~min}$. The $\mathrm{ZnO} / \mathrm{ITO}$ and $\mathrm{ZnO} / \mathrm{PS} / \mathrm{rGO} / \mathrm{ITO}$ film with an active area of $0.64 \mathrm{~cm}^{2}$ was used as working electrodes. Additionally, $\mathrm{Pt}$ wire and $\mathrm{Ag} / \mathrm{AgCl}$ electrodes were used as the counter electrode and the reference electrode, respectively. Moreover, $0.2 \mathrm{M} \mathrm{Na}_{2} \mathrm{SO}_{4}$ was used as an electrolyte for the electrochemical studies. The potential of the working electrode was set at $0 \mathrm{~V}$ against the Pt wire counter electrode. The DC conductivity of the samples was measured by the four-point collinear probe method using Keithley 4200-SCS.

\section{Results and discussion}

\subsection{Structural and microstructural analysis}

Fig. 1(a and b) represents the X-ray diffractograms of graphite, $\mathrm{GO}, \mathrm{rGO}, \mathrm{PS}, \mathrm{PS} / \mathrm{rGO}$, and $\mathrm{ZnO} / \mathrm{PS} / \mathrm{rGO}$ composites. The characteristic strong intensity peak corresponding to the interlayer 

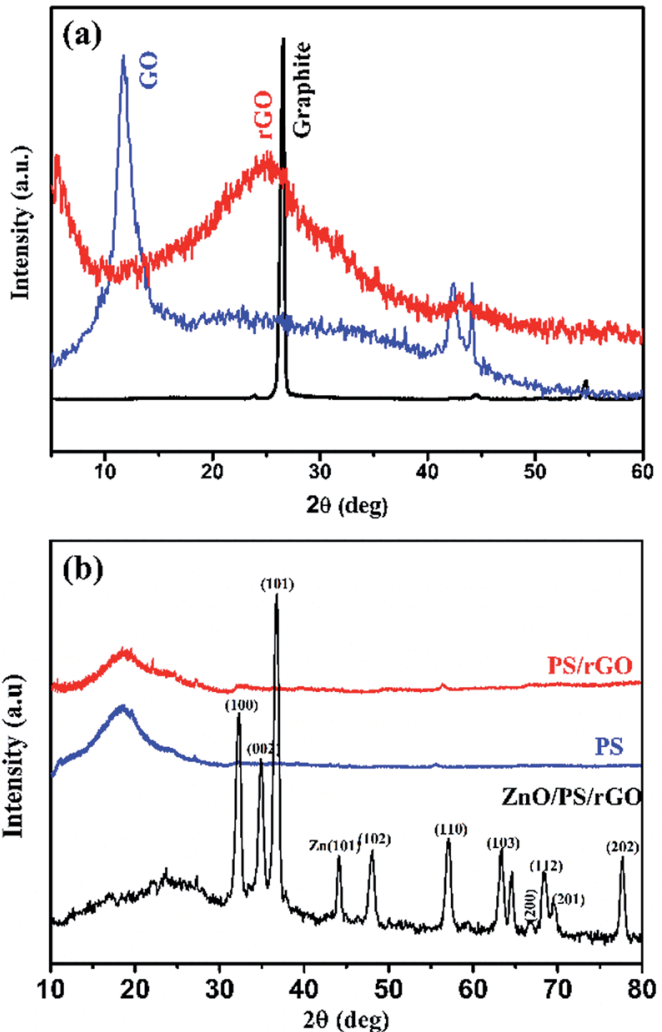

Fig. 1 XRD spectra of (a) graphite, GO, and $\mathrm{rGO}$ and those of (b) PS, $\mathrm{PS} / \mathrm{rGO}$, and $\mathrm{ZnO} / \mathrm{PS} / \mathrm{rGO}$.

spacing of graphite $\left(0.335 \mathrm{~nm}\right.$ observed at $\left.26.5^{\circ}\right)$ shifted to $11.6^{\circ}$ after its oxidation (GO), indicating a significant increase in the interlayer spacing of $0.761 \mathrm{~nm}$ due to the attachment of oxygen functional groups between graphitic layers. The peaks corresponding to GO, observed at $42^{\circ}$ and $45^{\circ}$, originated from the unreacted graphitic phases present in GO. ${ }^{34}$ The XRD pattern of rGO displays a weak and broad diffraction peak at $25.08^{\circ}$, showing a reduced interlayer spacing of $0.354 \mathrm{~nm}$ due to the removal of oxygen functional groups from $\mathrm{GO}^{35}$ The XRD pattern of PS shows a broad peak at $19.7^{\circ}$, attributed to the weak intermolecular van der Waals forces induced by the polymer chains. ${ }^{36,37}$ The peaks corresponding to the hexagonal wurtzite lattice of $\mathrm{ZnO}^{38}$ is discernible in the XRD pattern of the $\mathrm{ZnO} / \mathrm{PS} /$ rGO composite. Additionally, the background hump between $11.6^{\circ}$ and $30^{\circ}$ in the XRD pattern of the $\mathrm{ZnO} / \mathrm{PS} / \mathrm{rGO}$ composite is due to the presence of the PS matrix.

Fig. 2(a-d) shows the SEM images of GO, rGO, PS/rGO, and $\mathrm{ZnO} / \mathrm{PS} / \mathrm{rGO}$ composites, and Fig. 2(e and f) displays the TEM images of the $\mathrm{ZnO} / \mathrm{PS} / \mathrm{rGO}$ composite. As inferred from the SEM images of GO and rGO (Fig. 2(a and b)), the characteristic wavelike morphology was observed. In Fig. 2(b), it can be observed that the wave-like morphology is not as smooth as that shown in Fig. 2(a). This indicates the re-stacking of the individual sheets via van der Waals interactions after the removal of the oxygen functional groups from the basal planes and from the edges of GO. Furthermore, it is also evident from the XRD pattern of rGO that the $d$-spacing decreases after the reduction of GO.
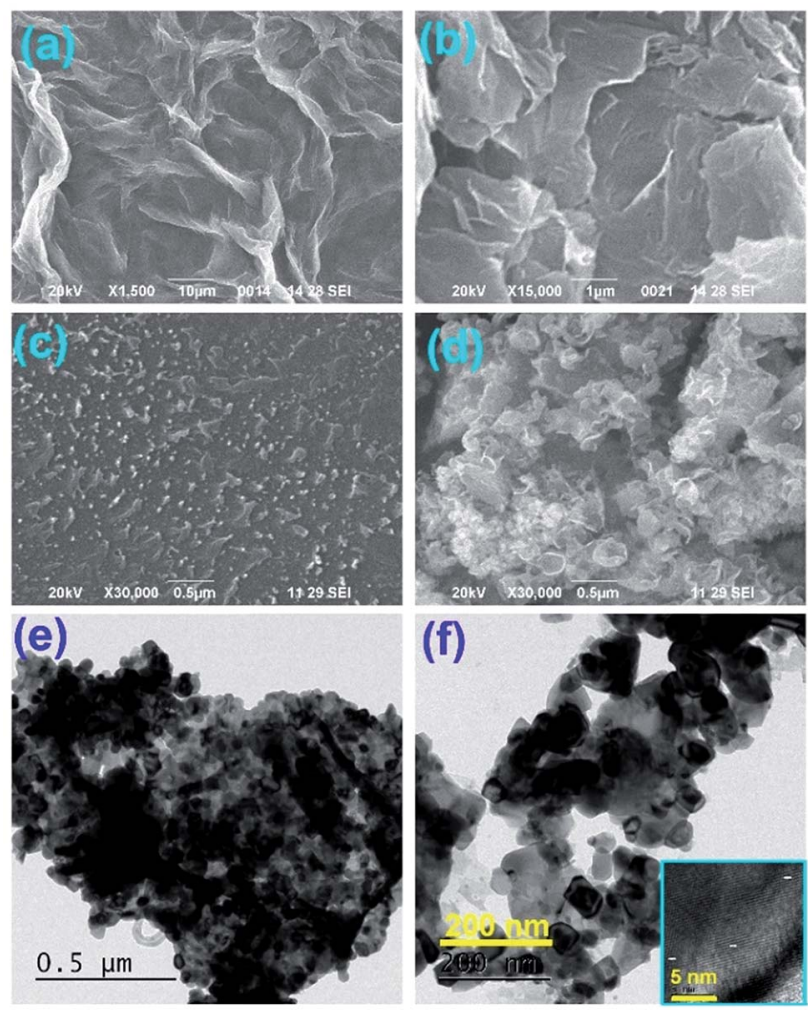

Fig. 2 SEM images of (a) GO, (b) rGO, (c) PS/rGO, and (d) ZnO/PS/rGO. TEM images of the $\mathrm{ZnO} / \mathrm{PS} / \mathrm{rGO}$ composite are shown in (e) $\&$ (f) and the inset shows the HR-TEM image.

The SEM image of PS/rGO displays the uniform dispersion of rGO on the PS matrix, suggesting the formation of the PS-rGO networks. On the other hand, the SEM image of the $\mathrm{ZnO} / \mathrm{PS} /$ rGO composite shows the decoration of $\mathrm{ZnO}$ in the composite. The HR TEM images of the $\mathrm{ZnO} / \mathrm{PS} / \mathrm{rGO}$ composite show well-defined $\mathrm{ZnO}$ lattice fringe separations of $0.23 \mathrm{~nm}$ and $0.21 \mathrm{~nm}$ corresponding to the (101) and (101) planes (as shown in the inset of Fig. 2(f)), which reveals the strong crystalline

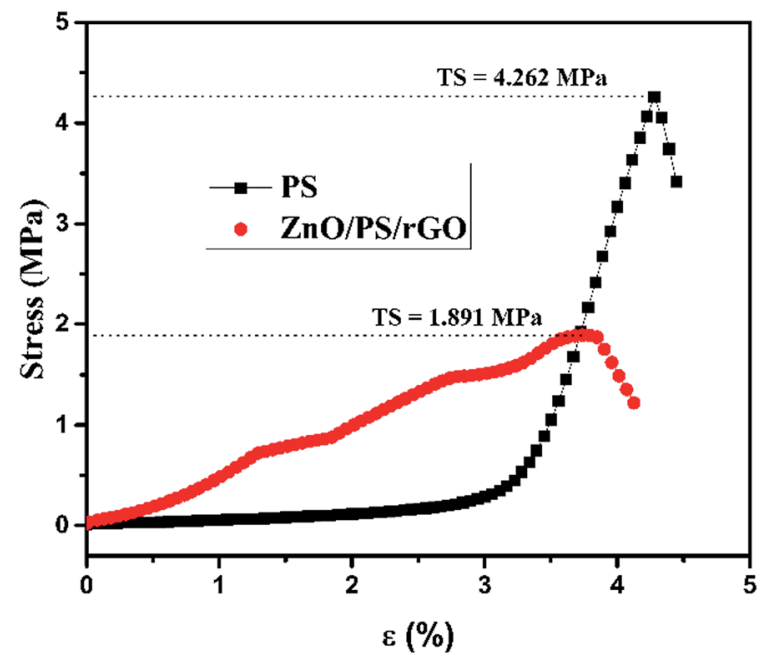

Fig. 3 Stress vs. \% elongation of the PS and $\mathrm{ZnO} / \mathrm{PS} / \mathrm{rGO}$ films. 
nature of the $\mathrm{ZnO}$ nanostructures in the composite. Furthermore, the $\mathrm{ZnO}$ nanoparticles were found to be uniformly dispersed in the composite.

Fig. 3 represents the tensile strength of the PS and $\mathrm{ZnO} / \mathrm{PS} /$ rGO films determined using ASTM D2256.

The tensile strength TS of PS and ZnO/PS/rGO are $4.262 \mathrm{MPa}$ and $1.891 \mathrm{MPa}$, respectively. It was observed that the tensile strength of PS reduced to $45 \%$ while the composite $\mathrm{ZnO} / \mathrm{PS} / \mathrm{rGO}$ was formed. The reduction in the tensile strength of the composite is due to the presence of $5 \mathrm{wt} \%$ of rGO and $40 \mathrm{wt} \%$ of $\mathrm{ZnO}$ in addition to $55 \mathrm{wt} \%$ of PS. Our results show that the $\mathrm{ZnO} /$ PS/rGO composite exhibits polymer characteristics such as tensile strength and percentage elongation. However, higher content of $\mathrm{ZnO}$ in the composite may lower the tensile properties of the composite.

\subsection{Spectral analysis}

3.2.1 FTIR and Raman spectral analysis. The FTIR spectra of GO, rGO, PS/rGO, and $\mathrm{ZnO} / \mathrm{PS} / \mathrm{rGO}$ composites are shown in Fig. 4(a and b). The following characteristic features of GO were observed: a carbonyl stretching vibration at $1720 \mathrm{~cm}^{-1}, \mathrm{C}-\mathrm{C}$ stretching at $1585 \mathrm{~cm}^{-1}$, a $\mathrm{C}-\mathrm{O}$ vibration of the $\mathrm{C}-\mathrm{OH}$ at 1220 $\mathrm{cm}^{-1}$, a C-O-C vibration in the epoxy groups at $1036 \mathrm{~cm}^{-1}$, and
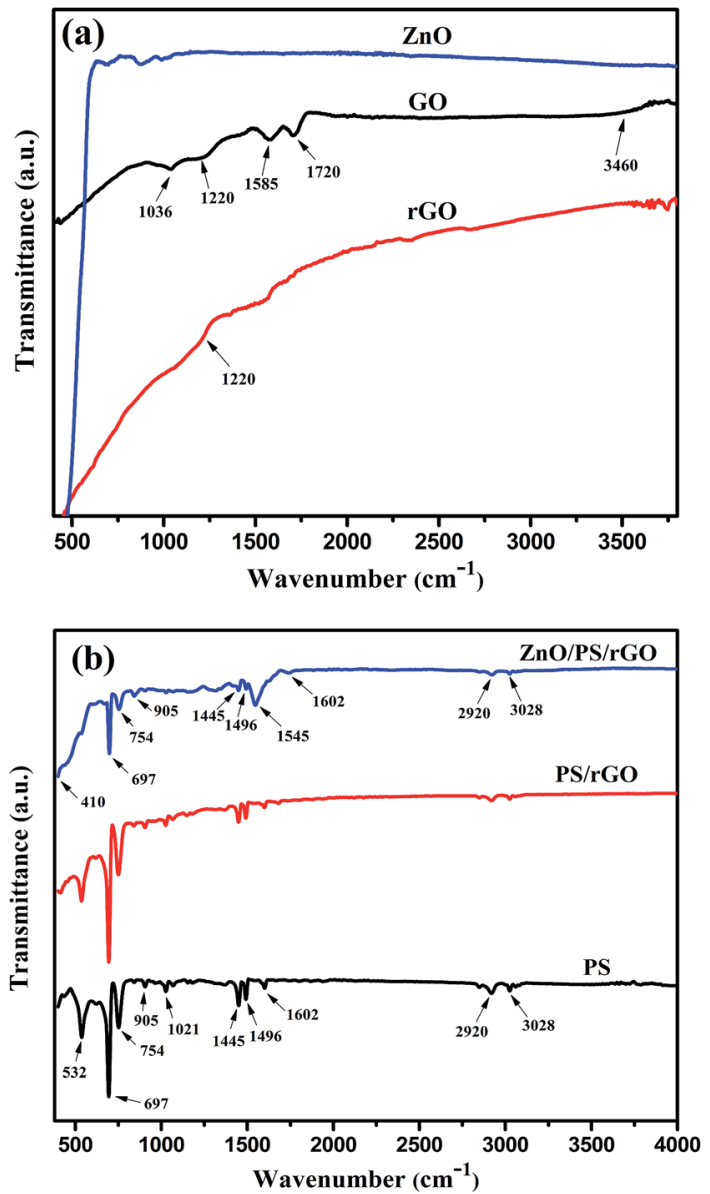

Fig. 4 FTIR spectra of (a) GO, rGO, and ZnO, and those of (b) PS, PS/ $\mathrm{rGO}$, and $\mathrm{ZnO} / \mathrm{PS} / \mathrm{rGO}$. an $\mathrm{O}-\mathrm{H}$ stretching vibration at $3460 \mathrm{~cm}^{-1}$. After reduction, the intensity of the oxygen-containing groups in the rGO, PS/rGO, and $\mathrm{ZnO} / \mathrm{PS} / \mathrm{rGO}$ composites remarkably decreased as compared to that of GO, indicating an effective reduction of GO via hydrazine hydrate. For the $\mathrm{PS} / \mathrm{rGO}$ and $\mathrm{ZnO} / \mathrm{PS} / \mathrm{rGO}$ composites, the spectral intensity representing the oxygencontaining functional groups became very weak and newly emerged characteristic spectral peaks were prominently observed.

The series of strong peaks at the wavenumbers 3028, 2920, 1602, 1496, 1445, 1021, 905, 754, 697, and $532 \mathrm{~cm}^{-1}$ correspond to the characteristic peaks of benzene in PS, ${ }^{32}$ thus confirming the presence of PS in the composite. Furthermore, the two additional peaks observed in the $\mathrm{ZnO} / \mathrm{PS} / \mathrm{rGO}$ composite at 1545 $\mathrm{cm}^{-1}$ and $410 \mathrm{~cm}^{-1}$ correspond to the skeleton in-plane vibration of $\mathrm{C}=\mathrm{C}^{39}$ and the $\mathrm{Zn}-\mathrm{O}$ stretching vibration, ${ }^{40}$ respectively.

Fig. 5 displays the Raman spectra of GO, rGO, PS/rGO, and $\mathrm{ZnO} / \mathrm{PS} / \mathrm{rGO}$ composites obtained in the spectral range from 1000 to $2500 \mathrm{~cm}^{-1}$. The D-band and G-band peaks of GO were observed at $1322 \mathrm{~cm}^{-1}$ and $1595 \mathrm{~cm}^{-1}$, respectively. However, for rGO, there was a slight shift in the D-band and the G-band, which were observed at $1317 \mathrm{~cm}^{-1}$ and $1591 \mathrm{~cm}^{-1}$, respectively. The $\mathrm{D} / \mathrm{G}$ band intensity $\left(I_{\mathrm{D}} / I_{\mathrm{G}}\right)$ ratio decreases from 1.41 to 1.27 after the reduction of GO. This signifies decrease in the defect densities of GO after its reduction. For the PS/rGO composite, the D-band and G-band peaks were observed at $1310 \mathrm{~cm}^{-1}$ and $1595 \mathrm{~cm}^{-1}$, respectively, with the $I_{\mathrm{D}} / I_{\mathrm{G}}$ ratio of 1.3 , slightly higher than that of rGO. This could be ascribed to the noncovalent $\pi-\pi$ interactions between the PS scaffold and basal planes of rGO. ${ }^{41}$ However, for the $\mathrm{ZnO} / \mathrm{PS} / \mathrm{rGO}$ composite, the $I_{\mathrm{D}} / I_{\mathrm{G}}$ ratio is 1.4, higher than that observed for PS/rGO due to the difference in the concentration of PS in the composite. In $\mathrm{ZnO} /$ $\mathrm{PS} / \mathrm{rGO}$, the concentration of PS is $55 \mathrm{wt} \%$, whereas in the PS/ rGO composite, it is $95 \mathrm{wt} \%$.

3.2.2 UV-vis \& PL analysis. Fig. 6(a and b) presents the representative UV-vis absorption and the PL spectra of rGO, PS, $\mathrm{PS} / \mathrm{rGO}, \mathrm{ZnO}$, and $\mathrm{ZnO} / \mathrm{PS} / \mathrm{rGO}$ composites. In the UV-vis spectra, a strong absorption peak at $262 \mathrm{~nm}$ and a broad peak

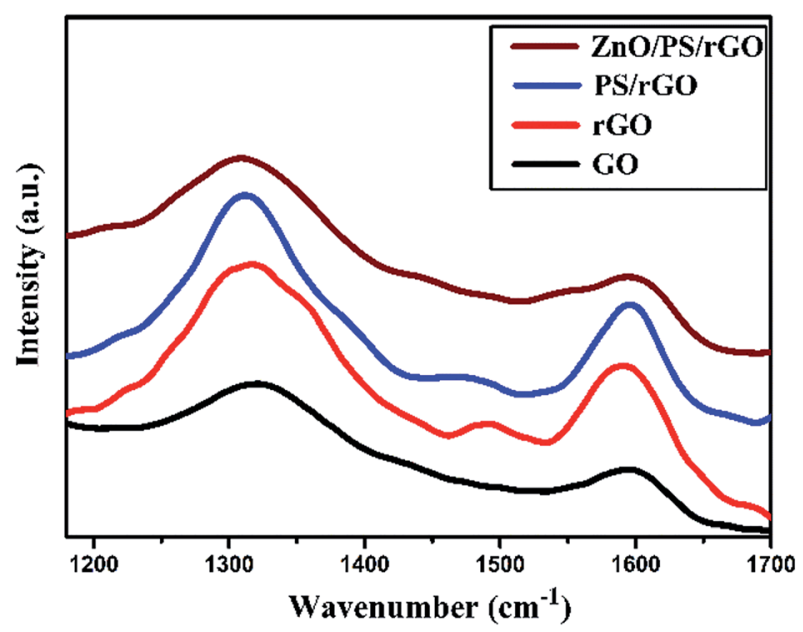

Fig. 5 Raman spectra of GO, rGO, PS/rGO, and $\mathrm{ZnO} / \mathrm{PS} / \mathrm{rGO}$. 
at $295 \mathrm{~nm}$ were observed, corresponding to the $\pi-\pi^{*}$ transition of the $\mathrm{C}=\mathrm{C}$ bond and the $\mathrm{n}-\pi^{*}$ transition of the $\mathrm{C}=\mathrm{O}$ bond in rGO, respectively. The peak observed at $262 \mathrm{~nm}$ for rGO is the red shift peak of GO at $230 \mathrm{~nm}$, confirming the effective reduction of GO in the composite and the restoration of $\pi$ conjugation of rGO. Moreover, the disappearance of the $295 \mathrm{~nm}$ plasmon peak, ${ }^{42}$ corresponding to $\mathrm{rGO}$ in the $\mathrm{PS} / \mathrm{rGO}$ composite, confirms the effective removal of the oxygen-
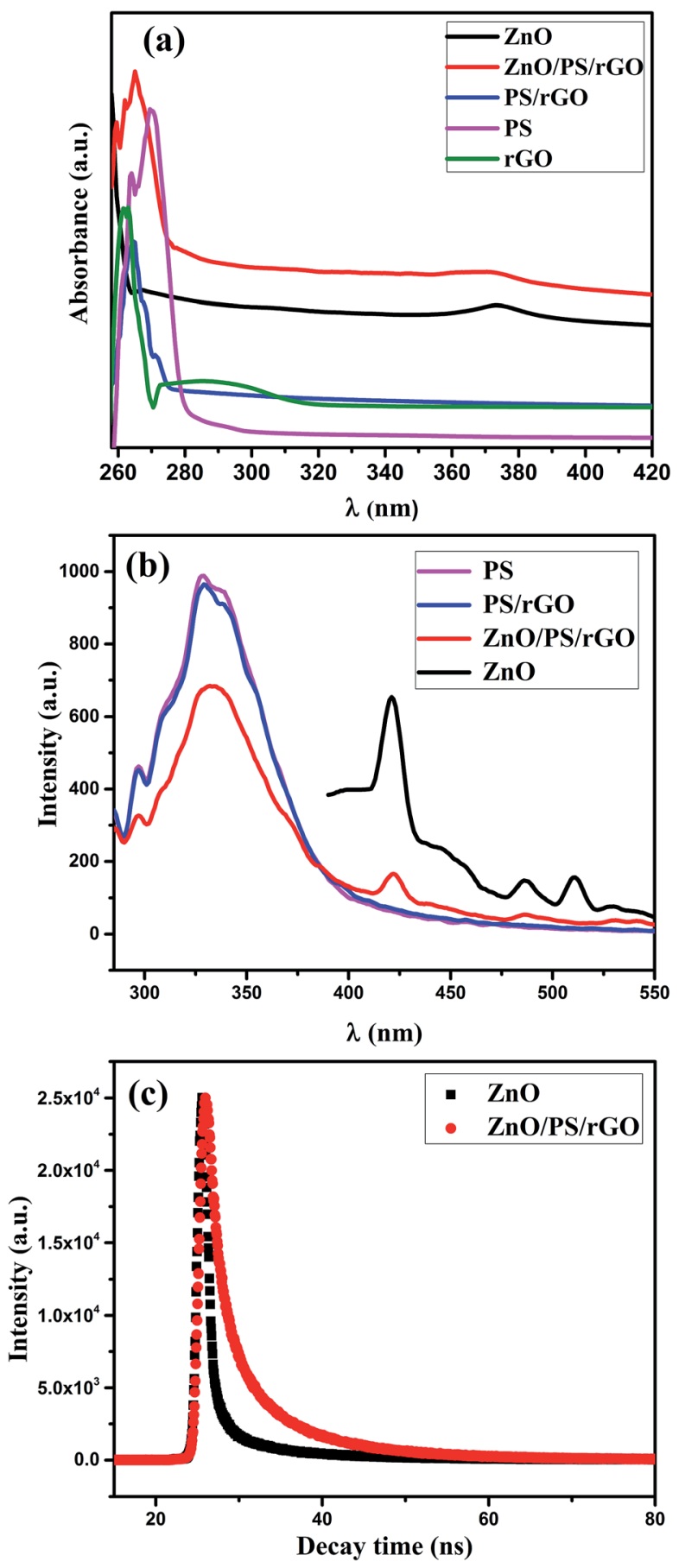

Fig. 6 Spectral analysis of the composites: (a) UV-vis spectra, (b) PL emission spectra, and (c) time-resolved PL spectra corresponding to an excitation wavelength of $340 \mathrm{~nm}$. containing groups after its reduction via hydrazine hydrate. As noticed in Fig. 5(a), a UV-absorption peak of $\mathrm{ZnO}$ is observed at $372 \mathrm{~nm}$ (optical bandgap of $3.33 \mathrm{eV}$ ) in the $\mathrm{ZnO} / \mathrm{PS} / \mathrm{rGO}$ composite, suggesting that there is no change in the optical band gap of $\mathrm{ZnO}$ in the composite. The room temperature PL spectra of PS, PS/rGO, and ZnO/PS/rGO composites, obtained in the range of 290-550 nm, show a PL emission peak at $332 \mathrm{~nm}$ with an excitation wavelength of $265 \mathrm{~nm}$. Additionally, emission peaks of $\mathrm{ZnO}$ were observed in the $\mathrm{ZnO} / \mathrm{PS} / \mathrm{rGO}$ composite. For comparison, the PL emission spectra of pristine $\mathrm{ZnO}$ corresponding to an excitation wavelength of $370 \mathrm{~nm}$ is shown in the Fig. 6(b). The emission peaks due to the intrinsic defects in the ZnO crystal were observed at $422 \mathrm{~nm}, 485$, and $510 \mathrm{~nm} .^{\mathbf{4 3 4}}$ The intrinsic defects in $\mathrm{ZnO}$ are advantageous for the enhancement of the photocurrent density of the $\mathrm{ZnO} / \mathrm{PS} / \mathrm{rGO}$ composite. ${ }^{45}$

The exponential decay curves corresponding to the lifetime of the photoexcited charge carriers, demonstrated by timeresolved photoluminescence decay studies of pristine $\mathrm{ZnO}$ and $\mathrm{ZnO} / \mathrm{PS} / \mathrm{rGO}$, are shown in Fig. 6(c). The fitted parameters determined from the time-resolved PL spectra of $\mathrm{ZnO}$ and the $\mathrm{ZnO} / \mathrm{PS} / \mathrm{rGO}$ composite are presented in Table 1.

Furthermore, the average lifetime of the composites can be calculated using the following expression; ${ }^{46}$

$$
<\tau>=\Sigma_{i} B_{i} \tau_{i} \text { (second) }
$$

The calculated average lifetime of the excited charge carriers in pristine $\mathrm{ZnO}$ and $\mathrm{ZnO} / \mathrm{PS} / \mathrm{rGO}$ is $0.1029 \mathrm{~ns}$ and $2.599 \mathrm{~ns}$, respectively. The significant improvement in the lifetime of the excited charge carriers in the $\mathrm{ZnO} / \mathrm{PS} / \mathrm{rGO}$ composite reflects its better electron transport properties. ${ }^{47}$ It becomes evident that the presence of polymer and graphene in the $\mathrm{ZnO} / \mathrm{PS} / \mathrm{rGO}$ composite increases the excited charge carrier's lifetime and hence favors the rapid charge carrier transport properties of the composite.

\subsection{Thermogravimetric analysis}

The thermal stability of GO, rGO, PS/rGO, and ZnO/PS/rGO composites was analyzed using TGA at the dynamic heating rate of $10{ }^{\circ} \mathrm{C} \mathrm{min}^{-1}$. Fig. 7 presents the representative TGA curves of GO, rGO, PS/rGO, and $\mathrm{ZnO} / \mathrm{PS} / \mathrm{rGO}$ composites. A 15\% weight loss was observed for $\mathrm{GO}$ below $100{ }^{\circ} \mathrm{C}$, which might be due to the removal of surface adsorbed moisture and impurity gases. Nearly, $20 \%$ weight loss was observed at $\sim 200{ }^{\circ} \mathrm{C}$, which is presumably due to pyrolysis of the labile oxygen-containing functional groups. ${ }^{\mathbf{4 1}}$ The gradual weight loss observed between $200{ }^{\circ} \mathrm{C}$ and $600{ }^{\circ} \mathrm{C}$ might have resulted from the decomposition of carboxyl, hydroxyl, and epoxy groups at the edge and basal planes of GO. ${ }^{48}$

Table 1 Fitted time-resolved PL spectral parameters

\begin{tabular}{llllllll}
\hline Sample & $B_{1}$ & $\tau_{1}(\mathrm{~ns})$ & $B_{2}$ & $\tau_{2}(\mathrm{~ns})$ & $B_{3}$ & $\tau_{3}(\mathrm{~ns})$ & $<\tau>(\mathrm{ns})$ \\
\hline ZnO & 0.007 & 1.74 & 1.03 & 0.07 & 0.001 & 11.13 & 0.10 \\
$\mathrm{ZnO} / \mathrm{PS} / \mathrm{rGO}$ & 0.013 & 6.88 & 0.05 & 1.14 & 0.001 & 19.04 & 2.59
\end{tabular}




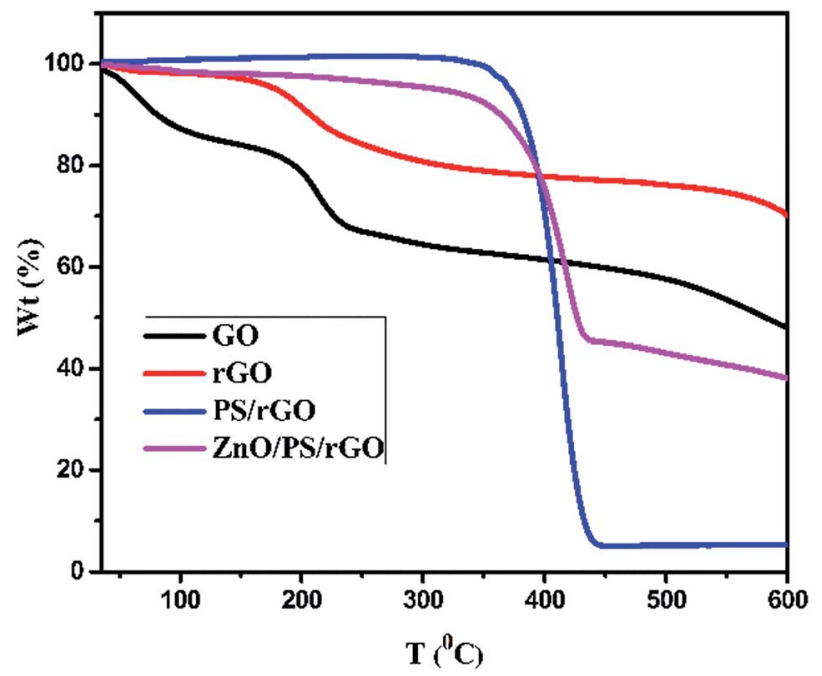

Fig. 7 TGA spectra of GO, rGO, PS/rGO, and $\mathrm{ZnO} / \mathrm{PS} / \mathrm{rGO}$ composites.

As can be seen from Fig. 7, below $200{ }^{\circ} \mathrm{C}$, rGO is much more thermally stable than GO due to the removal of the residual water molecules trapped in the interlayered space that leave behind few oxygen-containing functionalities between layers of rGO after a two-step chemical and thermal reduction process. For the PS/rGO composite, the initial decomposition of PS starts at $\sim 400{ }^{\circ} \mathrm{C}$, and it saturates at $440{ }^{\circ} \mathrm{C}$ with $\sim 95 \%$ weight loss, which might have resulted from the dissociation of the main chains in PS. ${ }^{41}$ There is a slight increase in the thermal decomposition temperature of the $\mathrm{ZnO} / \mathrm{PS} / \mathrm{rGO}$ composite due to the strong interaction between $\mathrm{PS} / \mathrm{rGO}$ and $\mathrm{ZnO}$. The slight weight loss noticed in the temperature range from 200 to $350{ }^{\circ} \mathrm{C}$ occurred due to the elimination of oxygen-containing groups in the $\mathrm{ZnO} / \mathrm{PS} / \mathrm{rGO}$ composite. Moreover, 55\% weight loss occurred at around $440{ }^{\circ} \mathrm{C}$, which is attributed to PS, $40 \mathrm{wt} \%$ of $\mathrm{ZnO}$, and $5 \mathrm{wt} \%$ of rGO present in the composite.

\subsection{DC conductivity and impedance analysis}

The DC conductivity of $\mathrm{ZnO}, \mathrm{PS} / \mathrm{rGO}$, and $\mathrm{ZnO} / \mathrm{PS} / \mathrm{rGO}$ was measured at $28{ }^{\circ} \mathrm{C}$ using the four-point collinear probe method with the probe spacing of $1.59 \mathrm{~mm}$. The resistivity of the sample was calculated using the following equation:

$$
\rho=\frac{\pi t}{\ln 2}\left(\frac{V}{I}\right) f_{1} f_{2}(\Omega \mathrm{cm})
$$

where, $f_{1}(t / s)$ - thickness correction factor, $f_{2}(d / s)$ - diameter correction factor $V / I$ - slope obtained from the graph, $s$ - probe spacing, $t$ - thickness of the pellet, $d$-diameter of the pellet.

Table 2 DC electrical conductivity of the samples

\begin{tabular}{llll}
\hline Samples & $\mathrm{ZnO}$ & $\mathrm{PS} / \mathrm{rGO}$ & $\mathrm{ZnO} / \mathrm{PS} / \mathrm{rGO}$ \\
$\begin{array}{l}\text { DC electrical conductivity } \\
\left(\mathrm{S} \mathrm{cm}^{-1}\right)\end{array}$ & $4.307 \times 10^{-7}$ & 0.03087 & 0.00195
\end{tabular}

$\left(\mathrm{S} \mathrm{cm}^{-1}\right)$
As given in Table 2, the electrical conductivity of pristine $\mathrm{ZnO}$ was determined to be $4.307 \times 10^{-7} \mathrm{~S} \mathrm{~cm}^{-1}$. This value is close to that reported for the room temperature conductivity of pure $\mathrm{ZnO}\left(7.261 \times 10^{-7} \mathrm{~S} \mathrm{~cm}^{-1}\right) .{ }^{11}$ However, the electrical conductivity of the PS/rGO composite having $5 \mathrm{wt} \% \mathrm{rGO}$ is $0.03087 \mathrm{~S}$ $\mathrm{cm}^{-1}$. Note that the conductivity of pure PS is about $2.45 \times$ $10^{-12} \mathrm{~S} \mathrm{~cm}^{-1}$, $^{9}$ significantly lower than that of the PS/rGO composite used in this study. The present study reveals that the conductivity of PS can be markedly improved with the addition of small amount of rGO ( $5 \mathrm{wt} \%$ rGO was used in the present investigation). Furthermore, significantly improved conductivity was observed for the $\mathrm{ZnO} / \mathrm{PS} / \mathrm{rGO}$ composite $\left(0.00195 \mathrm{~S} \mathrm{~cm}^{-1}\right)$, in which the amount of $\mathrm{ZnO}$ and $\mathrm{rGO}$ is 40 wt $\%$ and $5 \mathrm{wt} \%$, respectively (shown in Fig. 7). The electrical conductivity of the $\mathrm{ZnO} / \mathrm{PS} / \mathrm{rGO}$ composite is nearly 4500 times higher than that of pure $\mathrm{ZnO}$ because of a strong ambipolar field effect occurring in the polymer/graphene composite. ${ }^{29}$ The superior electrical conductivity of the $\mathrm{ZnO} / \mathrm{PS} / \mathrm{rGO}$ composite is more favorable for the collection of photoinduced electrons.

\subsection{AC impedance analysis}

To understand the electronic and optoelectronic properties of $\mathrm{ZnO}$, PS, PS/rGO, and ZnO/PS/rGO composites in detail, we carried out the AC-impedance spectral analysis. A pelletized sample of thickness $0.7 \mathrm{~mm}$ and an AC input frequency of $1 \mathrm{MHz}$ to $500 \mathrm{mHz}$ were used for the AC-impedance analysis. The Nyquist plots, comprising the imaginary part $\left(Z^{\prime}\right) v s$. the real part $\left(-Z^{\prime \prime}\right)$, of the impedance of the composites are shown in Fig. 8(a-c).

As presented in Fig. 8(b and c), the AC-impedance of the PS/ rGO composite and $\mathrm{ZnO} / \mathrm{PS} / \mathrm{rGO}$ exhibits much lower resistance than that of pristine PS and ZnO (Fig. 8(a)). The presence of 5 $\mathrm{wt} \% \mathrm{rGO}$ in the $\mathrm{ZnO} / \mathrm{PS} / \mathrm{rGO}$ composite markedly lowers the resistance value of the composite. The smaller radius of the semicircle observed in the AC-impedance spectra of the PS/rGO and $\mathrm{ZnO} / \mathrm{PS} / \mathrm{rGO}$ composite indicates better charge transfer efficiency. To find the enhancement in the conductivity of the composite as compared to that of its individual components, we determined the AC and DC conductivity of $\mathrm{ZnO}, \mathrm{PS}, \mathrm{PS} / \mathrm{rGO}$, and $\mathrm{ZnO} / \mathrm{PS} / \mathrm{rGO}$, and the corresponding details of the Nyquist plot are summarized in Table 3.

\subsection{Photocurrent analysis}

To investigate the improvement in the electron transportation kinetics of the $\mathrm{ZnO} / \mathrm{PS} / \mathrm{rGO}$ composite as compared to that of pristine $\mathrm{ZnO}$, the photocurrent transient response (PCTR) of the sample-coated electrodes were obtained. For the PCTR measurements, a sample (film) of thickness $\sim 12 \mu \mathrm{m}$ was prepared using the doctor-blading technique, and the photoconductivity of the samples was measured as a function of time. An input of $0 \mathrm{~V}$ with light on/off cycles with an interval of 15 seconds was employed. The measured dark current, photocurrent, and on-off difference of $\mathrm{ZnO} / \mathrm{PS} / \mathrm{rGO}$ and pristine $\mathrm{ZnO}$ are given in Table 4.

Thus, the photoconductivity of the $\mathrm{ZnO} / \mathrm{PS} / \mathrm{rGO}$ composite is improved by nearly 9 times that of pristine $\mathrm{ZnO}$. This significant enhancement in the photoconductivity of $\mathrm{ZnO}$ is due to the 

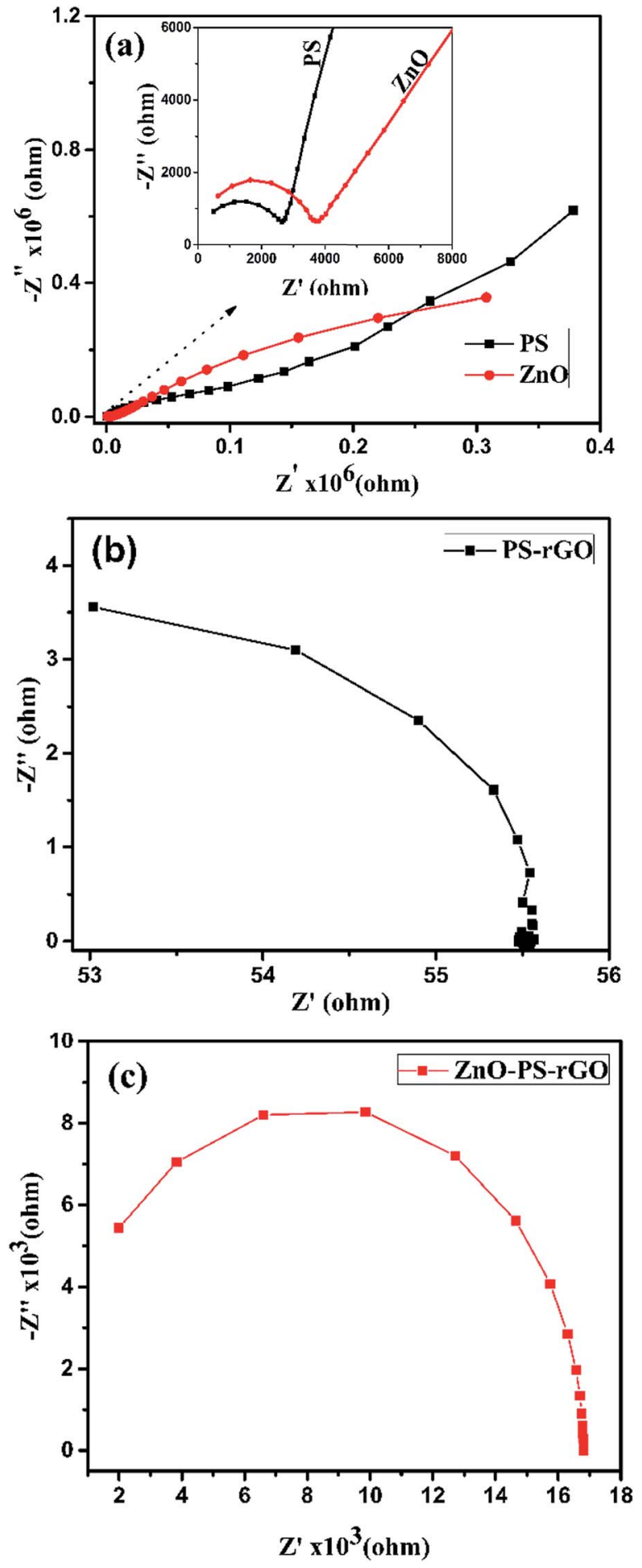

Fig. 8 Impedance spectra of (a) $\mathrm{ZnO}$ and PS (inset figure represents the magnified impedance curve of $\mathrm{ZnO}$ and $\mathrm{PS}$ at the lower impedance region) and those of the (b) PS/rGO composite and (c) ZnO/PS/rGO composite.

presence of the rGO/PS composite ( $5 \mathrm{wt} \%$ rGO). Moreover, photocurrent obtained from the illuminated semiconductor film $(\mathrm{ZnO})$ was determined by the speed of the excited electrons withdrawn from the semiconductor to the conducting electrode (ITO) and the recombination at the electrolyte/film interface. ${ }^{50}$
Table 3 AC impedance measurements of the samples

\begin{tabular}{lllll}
\hline Sample & $R_{1}(\Omega)$ & $R_{2}(\Omega)$ & $C_{1}(\mathrm{~F})$ & $C_{2}(\mathrm{~F})$ \\
\hline ZnO & $0.32 \times 10^{6}$ & 5619 & $0.377 \times 10^{-6}$ & $0.104 \times 10^{-9}$ \\
PS & $0.14 \times 10^{6}$ & 2626 & $0.308 \times 10^{-6}$ & $0.186 \times 10^{-9}$ \\
PS/rGO & 50 & - & $0.22 \times 10^{-9}$ & - \\
ZnO/PS/rGO & $16.8 \times 10^{3}$ & - & $25.79 \times 10^{-12}$ & -
\end{tabular}

Table 4 Photocurrent response measurements

\begin{tabular}{llll}
\hline Sample & $\begin{array}{l}\text { Dark current } \\
\left.(\mu \mathrm{A} \mathrm{cm})^{-2}\right)\end{array}$ & $\begin{array}{l}\text { Photocurrent } \\
\left(\mu \mathrm{A} \mathrm{cm}^{-2}\right)\end{array}$ & $\begin{array}{l}\text { On-off } \\
\text { difference }\left(\mu \mathrm{A} \mathrm{cm}^{-2}\right)\end{array}$ \\
\hline $\mathrm{ZnO} / \mathrm{PS} / \mathrm{rGO}$ & 0.1 & 24.2 & 24.1 \\
$\mathrm{ZnO}$ & 1.1 & 2.8 & 1.7
\end{tabular}

The significant enhancement of the photoresponse current of the $\mathrm{ZnO} / \mathrm{PS} / \mathrm{rGO}$ composite obtained in this study can be attributed to two factors: the higher separation efficiency of the photoinduced electron-hole pairs and the lower recombination rate, resulting from the interaction between $\mathrm{ZnO}$ and PS/rGO. The higher separation efficiency is supported by the opencircuit voltage decay (OCVD) measurements and the lower recombination rate is evidenced from the charge transfer resistance on the surface, as demonstrated by the AC impedance measurements.

The photoinduced electron recombination property can be characterized using OCVD measurements. ${ }^{51}$ The electron recombination kinetics were investigated by monitoring the $V_{\mathrm{OC}}$ as a function of time after illuminating the light for 4 seconds with steady voltage. Photocurrent curves, OCVD curves, and electron lifetime curves of $\mathrm{ZnO}$ and the $\mathrm{ZnO} / \mathrm{PS} / \mathrm{rGO}$ composite are presented in Fig. 9(a-c). Fig. 9(b) displays the calculated lifetime of the photogenerated electrons $\left(\tau_{n}\right)$ as a function of $V_{\mathrm{OC}}$ for the $\mathrm{ZnO}$ and $\mathrm{ZnO} / \mathrm{PS} / \mathrm{rGO}$ composites.

As inferred from Fig. 9(b), after 4 seconds, when the illumination was switched off, there was a sharp decay in $V_{\mathrm{OC}}$ due to the recombination of charge carriers, which was related to the electron lifetime. ${ }^{52,53}$ The average lifetime of the photogenerated electrons can be calculated using the following equation (eqn. (3))..$^{54,55}$

$$
\tau_{n}=-\frac{K_{\mathrm{B}} T}{e}\left(\frac{\mathrm{d} V_{\mathrm{OC}}}{\mathrm{d} t}\right)^{-1} \text { second }
$$

where, $K_{\mathrm{B}}-$ Boltzmann constant, $T$ - temperature in Kelvin, $e-$ charge of the electron.

It becomes evident that the electron lifetime $\left(\tau_{n}\right)$ of $\mathrm{ZnO} / \mathrm{PS} /$ rGO is significantly larger than that of pristine $\mathrm{ZnO}$. The larger electron lifetime signifies slower electron recombination rate of photogenerated electrons; hence, more electrons might be surviving from the back-reaction, resulting in an improvement in the photocurrent. However, the $V_{\text {OC }}$ decay rate determined for the $\mathrm{ZnO} / \mathrm{PS} / \mathrm{rGO}$ composite is significantly lower than that of $\mathrm{ZnO}$, suggesting much slower electron recombination kinetics in the composite, which might be beneficial for optoelectronic applications. 

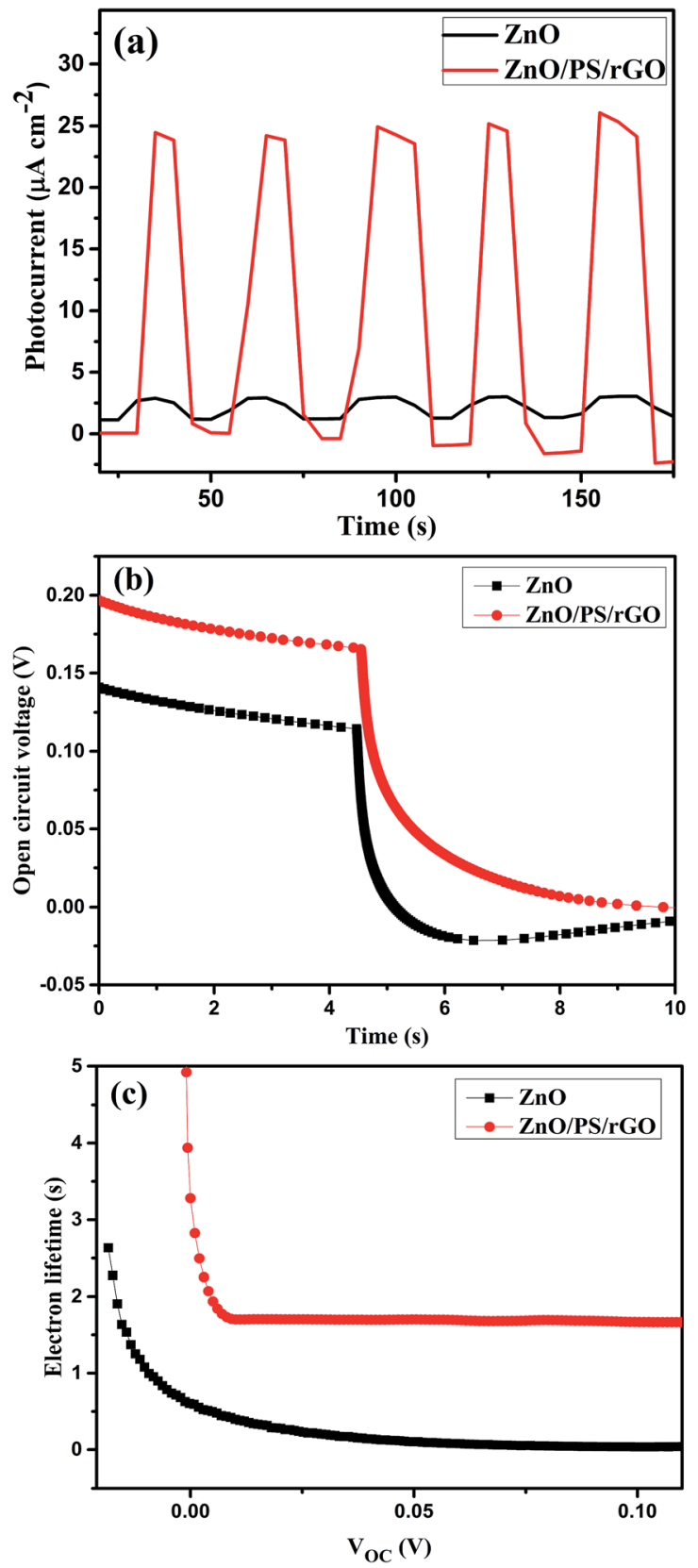

Fig. 9 (a) Photocurrent curves, (b) OCVD curves, and (c) electron lifetime curves of $\mathrm{ZnO}$ and $\mathrm{ZnO} / \mathrm{PS} / \mathrm{rGO}$.

\section{Conclusions}

Herein, the $\mathrm{ZnO} / \mathrm{PS} / \mathrm{rGO}$ (having $40 \mathrm{wt} \% \mathrm{ZnO}, 55 \mathrm{wt} \%$ PS, and 5 wt\% rGO) composite was successfully synthesized by a reflex method. It has been observed that as compared to pure $\mathrm{ZnO}$, the $\mathrm{ZnO} / \mathrm{PS} / \mathrm{rGO}$ composite exhibits excellent electrical conductivity. Furthermore, the composite exhibits a superior photocurrent of $24.2 \mu \mathrm{A} \mathrm{cm} \mathrm{cm}^{-2}$, whereas pristine $\mathrm{ZnO}$ exhibits a photocurrent of only $2.8 \mu \mathrm{A} \mathrm{cm} \mathrm{cm}^{-2}$. Thus, there is an enhancement in the photocurrent of $\mathrm{ZnO}$ by nearly 9 times when the $\mathrm{ZnO} / \mathrm{PS} / \mathrm{rGO}$ composite is made. These improved electrical and photovoltaic behaviors of the $\mathrm{ZnO} / \mathrm{PS} / \mathrm{rGO}$ composite can be attributed to the enhanced electrical conductivity and charge transportation kinetics due to the presence of rGO. Additionally, as confirmed from the timeresolved PL measurements, the composite has a larger electron lifetime of $2.5 \mathrm{~ns}$ as compared to $0.1 \mathrm{~ns}$ for pristine $\mathrm{ZnO}$. Furthermore, tensile property measurement of the composite reveals that the composite exhibits polymer characteristics, such as tensile strength and elongation, which is advantageous for making flexible electrodes.

\section{Acknowledgements}

The authors thankfully acknowledge the Department of Science and Technology, New Delhi, for financial support (IFA12-PH-18). We would also like to thank the Central University of Tamil Nadu (CUTN), Thiruvarur, and Banaras Hindu University (BHU), Varanasi, for providing experimental facilities. The authors also acknowledge Prof. P. Ravindran (CUTN), Prof. A. P. Dash (CUTN), and Prof. O. N. Srivastava (BHU) for their support and encouragement.

\section{References}

1 X. Liao, X. Yan, P. Lin, S. Lu, Y. Tian and Y. Zhang, ACS Appl. Mater. Interfaces, 2015, 7, 1602-1607.

2 B. Wu, Z. Wu, Q. Yang, F. Zhu, T. W. Ng, C. S. Lee, S. H. Cheung and S. K. So, ACS Appl. Mater. Interfaces, 2016, 8, 14717-14724.

3 M. Grätzel, Platinum Met. Rev., 1994, 38, 151-159.

4 M. Azarang, A. Shuhaimi, R. Yousefi and M. Sookhakian, J. Appl. Phys., 2014, 116, 084307.

5 Y.-L. Chen, Z.-A. Hu, Y.-Q. Chang, H.-W. Wang, Z.-Y. Zhang, Y.-Y. Yang and H.-Y. Wu, J. Phys. Chem. C, 2011, 115, 25632571.

$6 \mathrm{H}$. Abdullah, N. A. Atiqah, A. Omar, I. Asshaari, S. Mahalingam, Z. Razali, S. Shaari, J. Mandeep and H. Misran, J. Mater. Sci.: Mater. Electron., 2015, 26, 22632270.

7 Q. Zhang, C. S. Dandeneau, X. Zhou and G. Cao, Adv. Mater., 2009, 21, 4087-4108.

8 Ü. Özgür, Y. I. Alivov, C. Liu, A. Teke, M. Reshchikov, S. Doğan, V. Avrutin, S.-J. Cho and H. Morkoc, J. Appl. Phys., 2005, 98, 11.

9 H. Bae, M. Yoon, J. Kim and S. Im, Appl. Phys. Lett., 2003, 83, 5313-5315.

10 Z. Seow, A. Wong, V. Thavasi, R. Jose, S. Ramakrishna and G. Ho, Nanotechnology, 2008, 20, 045604.

11 M. Caglar, S. Ilican, Y. Caglar and F. Yakuphanoglu, Appl. Surf. Sci., 2009, 255, 4491-4496.

12 J. Lee, J. H. Hwang, J. Mashek, T. Mason, A. Miller and R. Siegel, J. Mater. Res., 1995, 10, 2295-2300.

13 Q. P. Luo, X. Y. Yu, B. X. Lei, H. Y. Chen, D. B. Kuang and C. Y. Su, J. Phys. Chem. C, 2012, 116, 8111-8117.

14 A. A. Balandin, S. Ghosh, W. Bao, I. Calizo, D. Teweldebrhan, F. Miao and C. N. Lau, Nano Lett., 2008, 8, 902-907. 
15 D. A. Dikin, S. Stankovich, E. J. Zimney, R. D. Piner, G. H. Dommett, G. Evmenenko, S. T. Nguyen and R. S. Ruoff, Nature, 2007, 448, 457-460.

16 I. Ovid'ko, Rev. Adv. Mater. Sci., 2013, 34, 1-11.

17 S. Stankovich, D. A. Dikin, G. H. Dommett, K. M. Kohlhaas, E. J. Zimney, E. A. Stach, R. D. Piner, S. T. Nguyen and R. S. Ruoff, Nature, 2006, 442, 282-286.

18 D. Fan, Y. Liu, J. He, Y. Zhou and Y. Yang, J. Mater. Chem., 2012, 22, 1396-1402.

19 E. Tkalya, M. Ghislandi, A. Alekseev, C. Koning and J. Loos, J. Mater. Chem., 2010, 20, 3035-3039.

20 K. S. Novoselov, A. K. Geim, S. V. Morozov, D. Jiang, Y. Zhang, S. V. Dubonos, I. V. Grigorieva and A. A. Firsov, Science, 2004, 306, 666-669.

21 M. D. Stoller, S. Park, Y. Zhu, J. An and R. S. Ruoff, Nano Lett., 2008, 8, 3498-3502.

22 R. R. Nair, P. Blake, A. N. Grigorenko, K. S. Novoselov, T. J. Booth, T. Stauber, N. M. Peres and A. K. Geim, Science, 2008, 320, 1308.

23 C. Lee, X. Wei, J. W. Kysar and J. Hone, Science, 2008, 321, 385-388.

24 K. M. Shahil and A. A. Balandin, Solid State Commun., 2012, 152, 1331-1340.

25 H. Chen, M. B. Müller, K. J. Gilmore, G. G. Wallace and D. Li, Adv. Mater., 2008, 20, 3557-3561.

26 H. Quan, B.-q. Zhang, Q. Zhao, R. K. Yuen and R. K. Li, Composites, Part A, 2009, 40, 1506-1513.

27 S. H. Domingues, R. V. Salvatierra, M. M. Oliveira and A. J. Zarbin, Chem. Commun., 2011, 47, 2592-2594.

28 C. L. Scott, G. Zhao and M. Pumera, Electrochem. Commun., 2010, 12, 1788-1791.

29 G. Eda and M. Chhowalla, Nano Lett., 2009, 9, 814-818.

30 A. S. Patole, S. P. Patole, H. Kang, J.-B. Yoo, T. H. Kim and J. H. Ahn, J. Colloid Interface Sci., 2010, 350, 530-537.

31 H. Hu, X. Wang, J. Wang, L. Wan, F. Liu, H. Zheng, R. Chen and C. Xu, Chem. Phys. Lett., 2010, 484, 247-253.

32 N. Wu, X. She, D. Yang, X. Wu, F. Su and Y. Chen, J. Mater. Chem., 2012, 22, 17254-17261.

33 J. Zhao, S. Pei, W. Ren, L. Gao and H. M. Cheng, ACS Nano, 2010, 4, 5245-5252.

34 N. R. Yogamalar, K. Sadhanandam, A. C. Bose and R. Jayavel, RSC Adv., 2015, 5, 16856-16869.
35 S. Pei, J. Zhao, J. Du, W. Ren and H. M. Cheng, Carbon, 2010, 48, 4466-4474.

36 C. Ayyagari, D. Bedrov and G. D. Smith, Macromolecules, 2000, 33, 6194-6199.

37 J. Yang, M. Wu, F. Chen, Z. Fei and M. Zhong, J. Supercrit. Fluids, 2011, 56, 201-207.

38 N. Sakai, T. Miyasaka and T. N. Murakami, J. Phys. Chem. C, 2013, 117, 10949-10956.

39 R. Sharma, F. Alam, A. Sharma, V. Dutta and S. Dhawan, J. Phys. Chem. C, 2014, 2, 8142-8151.

40 S. Dong, Y. Li, J. Sun, C. Yu, Y. Li and J. Sun, Mater. Chem. Phys., 2014, 145, 357-365.

41 C. Chen, R. Li, L. Xu and D. Yan, RSC Adv., 2014, 4, 1739317400.

42 K. Muthoosamy, R. G. Bai, I. B. Abubakar, S. M. Sudheer, H. N. Lim, H. S. Loh, N. M. Huang, C. H. Chia and S. Manickam, Int. J. Nanomed., 2015, 10, 1505.

43 Y.-F. Gao, M. Nagai, Y. Masuda, F. Sato and K. Koumoto, J. Cryst. Growth, 2006, 286, 445-450.

44 A. Khan, W. M. Jadwisienczak and M. E. Kordesch, Phys. E, 2006, 33, 331-335.

45 M. Kavitha, P. Gopinath and H. John, Phys. Chem. Chem. Phys., 2015, 17, 14647-14655.

46 F. Zheng, W. L. Xu, H. D. Jin, X.-T. Hao and K. P. Ghiggino, RSC Adv., 2015, 5, 89515-89520.

47 Z. Haider, J. Y. Zheng and Y. S. Kang, Phys. Chem. Chem. Phys., 2016, 18, 19595-19604.

48 B. Rajagopalan and J. S. Chung, Nanoscale Res. Lett., 2014, 9, 535.

49 A. Grinou, Y. S. Yun and H. J. Jin, Macromol. Res., 2012, 20, 84-92.

50 N. J. Bell, Y. H. Ng, A. Du, H. Coster, S. C. Smith and R. Amal, J. Phys. Chem. C, 2011, 115, 6004-6009.

51 S. Yumitori, J. Mater. Sci., 2000, 35, 139-146.

52 C. Xu, P. H. Shin, L. Cao, J. Wu and D. Gao, Chem. Mater., 2009, 22, 143-148.

53 B. X. Lei, J. Y. Liao, R. Zhang, J. Wang, C.-Y. Su and D. B. Kuang, J. Phys. Chem. C, 2010, 114, 15228-15233.

54 A. Zaban, M. Greenshtein and J. Bisquert, ChemPhysChem, 2003, 4, 859-864.

55 J. Bisquert, A. Zaban, M. Greenshtein and I. Mora-Seró, J. Am. Chem. Soc., 2004, 126, 13550-13559. 